Aerodynamic journal bearing with a flexible, damped support operating at 7.2 million DN

This article has been downloaded from IOPscience. Please scroll down to see the full text article.

2011 J. Micromech. Microeng. 21104014

(http://iopscience.iop.org/0960-1317/21/10/104014)

View the table of contents for this issue, or go to the journal homepage for more

Download details:

IP Address: 134.58.253.57

The article was downloaded on 13/10/2011 at 16:49

Please note that terms and conditions apply. 


\title{
Aerodynamic journal bearing with a flexible, damped support operating at 7.2 million DN
}

\author{
Tobias Waumans, Jan Peirs, Farid Al-Bender and Dominiek Reynaerts \\ Department of Mechanical Engineering, Katholieke Universiteit Leuven, Celestijnenlaan 300B, \\ 3001 Leuven, Belgium \\ E-mail: tobias.waumans@mech.kuleuven.be
}

Received 5 April 2011, in final form 29 June 2011

Published 29 September 2011

Online at stacks.iop.org/JMM/21/104014

\begin{abstract}
This paper reports on the design, development and experimental validation of an aerodynamic journal bearing with a flexible, damped support operating at speeds up to 1.2 million rpm (= 7.2 million DN). In terms of the DN-number, this achievement represents to our knowledge a record for an air bearing of the self-acting type. Stabilization by means of a flexible, damped support therefore proves to be a promising solution to the dynamic stability problem of high-speed gas bearings. In order to select the support parameters in an optimal way, a stability study is performed leading to the formulation of a series of dimensionless design guidelines. The proposed implementation, which makes use of elastomeric O-rings in combination with a tunable squeeze-film damper, is discussed in detail. A method for the manufacturing of miniature bearing bushes with a wave-shaped film height profile is outlined. Experiments up to $683280 \mathrm{rpm}$ are performed with an air-driven turbine and up to $1203000 \mathrm{rpm}$ with a helium-driven turbine. Deceleration experiments are conducted in order to obtain an estimation of the frictional losses of the system.
\end{abstract}

(Some figures in this article are in colour only in the electronic version)

\section{Introduction}

High-speed bearings constitute a key component of an increasing number of applications. In rotating equipment such as machine tool spindles for printed circuit board (PCB)drilling and micro-milling, compact turbomachines and optical scanning equipment, a clear trend has become evident towards an increase in rotational speed and a continual downscaling. Gas-lubricated bearings offer, for these purposes, very specific advantages over other, more conventional bearing technologies. First of all, due to the limited number of components which constitute a gas bearing, they are very well suited for application at a small or miniature scale. Furthermore, they provide a clean, oil-free bearing solution characterized by virtually wear-free operation, low frictional losses and a wide operating temperature range.

These advantages come from the fact that both bearing members are, under normal operating conditions, completely separated by a thin gas film, typically ranging from a few micrometres up to $50 \mu \mathrm{m}$ in height. As a result of the generation of a positive pressure distribution in between both surfaces, the bearing is able to carry a load. This pressure generation can be the result of an external supply of pressurized air (aerostatic bearing), or of a combination of relative shearing motion and a converging gap height profile (self-acting or aerodynamic bearing) [1]. Disadvantages, of course, also exist. The low specific load-carrying capacity and limited damping are the result of the low viscosity of gases and of their compressible nature. For high-speed applications, however, the principal drawback concerns the dynamic stability problem. Successful application therefore requires control of the rotor-bearing dynamics so as to avoid instabilities in the operational speed range envisaged.

To demonstrate the potential application field of miniature, high-speed gas bearings, some application examples are given in the field of micro turbomachinery. First of all, turbomachines are able to generate or dissipate a large amount of power in a relatively small package when operated 


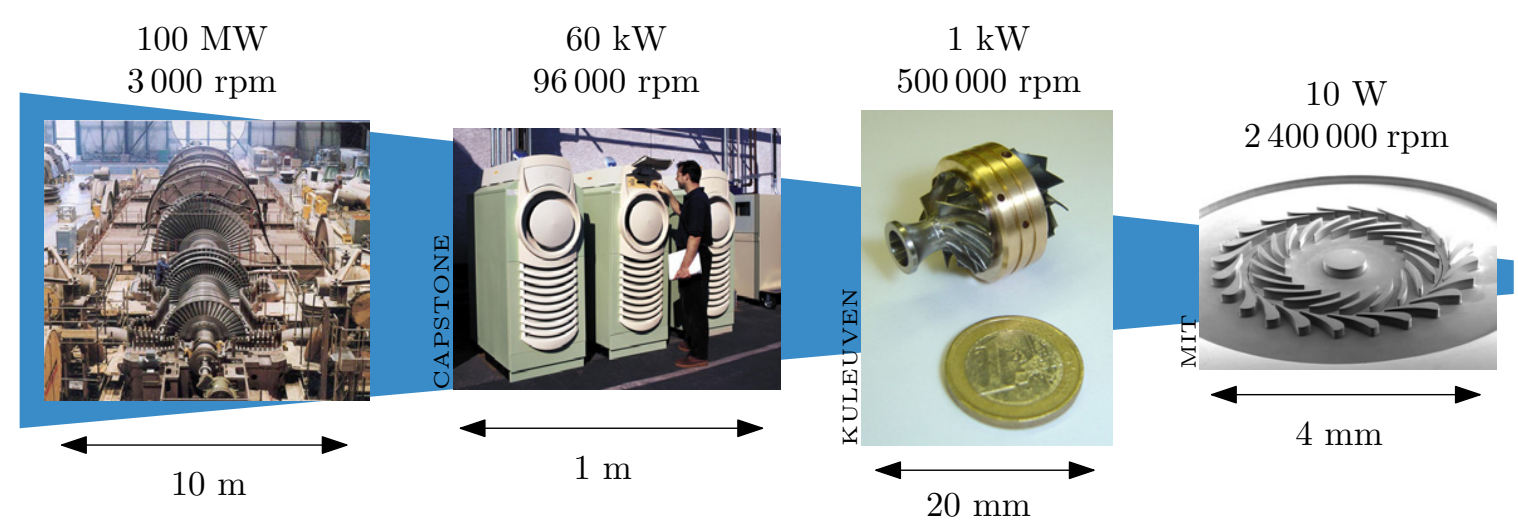

Figure 1. Different scales of gas turbines for electrical power generation. Downscaling affects the rotational speed in an inversely proportional way, stressing the need for new high-speed bearing solutions.

Table 1.Overview of high-speed achievements in order of increasing DN-number.

\begin{tabular}{|c|c|c|c|c|c|c|c|}
\hline Author(s) & Affiliation & Year & $\begin{array}{l}\text { Rotor } \\
\text { diameter } \\
(\mathrm{mm})\end{array}$ & $\begin{array}{l}\text { Rotational } \\
\text { speed } \\
\text { (rpm) }\end{array}$ & $\begin{array}{l}\text { DN- } \\
\text { number } \\
(\mathrm{mm} \text { rpm) }\end{array}$ & $\begin{array}{l}\text { Bearing } \\
\text { technology }\end{array}$ & References \\
\hline Signer H & Lewis Research Center & 1973 & 120 & 25000 & 3000000 & Ball bearing & [6] \\
\hline Zwyssig C & ETH Zurich/Celeroton & 2008 & 3.175 & 1000000 & 3175000 & Ball bearing & [7] \\
\hline Schmid C & Sulzer Brothers & 1974 & 22 & 222000 & 4884000 & Tilting pad $^{\mathrm{a}}$ & [8] \\
\hline \multirow[t]{2}{*}{ Hikichi K } & Tohoku University & 2003 & 4 & 1250000 & 5000000 & Hydroinertia & [9] \\
\hline & & 2009 & 8 & 642000 & 5136000 & Foil bearing & [10] \\
\hline Teo C J & MIT & 2006 & 4.2 & 1700000 & 7140400 & Externally pressurized $^{\mathrm{a}}$ & [11] \\
\hline Waumans T & K U Leuven & 2010 & 6 & 1203000 & 7218000 & Self-acting & [12] \\
\hline \multirow[t]{2}{*}{ Beams J W } & University of Virginia & 1937 & 9 & 1300000 & 11700000 & Externally pressurized $^{\mathrm{b}}$ & [13] \\
\hline & & 1946 & 0.521 & 37980000 & 20130000 & Magnetic ${ }^{\mathrm{c}}$ & [14] \\
\hline
\end{tabular}

${ }^{\mathrm{a}}$ Gas bearings supplied with or operated in helium.

${ }^{\mathrm{b}}$ Gas bearings supplied with hydrogen.

${ }^{c}$ Operated in vacuum.

at high speed. For this reason, research effort is oriented towards the development of (ultra)-micro gas turbines with an output power ranging from $10 \mathrm{~W}$ to a few $\mathrm{kW}[2,3]$ (figure 1). Possible applications concern portable electrical power generation, co-generation at a small scale or as a range extender for electrical cars. Small (turbo)compressors, on the other hand, may prove useful in more efficient oil-free heat pumps [4] and proton exchange membrane (PEM) fuel cells. Downscaling of all turbomachinery components, however, always affects the rotational speed in an inversely proportional way, as illustrated in figure 1 . As this creates new challenges for the bearing components, research needs to focus on the development of high-speed bearing technology at a miniature scale. Gas-lubricated bearings are a promising candidate on condition that the stability issue is tackled.

This paper will therefore treat the dynamic stability problem of high-speed gas bearings by addressing the following topics: (i) a stability study which results in the formulation of a convenient stability criterion; (ii) a brief discussion on measures to enhance the stability; (iii) a study on the stabilizing effect of a flexible, damped bearing support leading to the formulation of a series of generally applicable design guidelines; (iv) an outline of the proposed implementation of introducing external damping; and (v) experimental validation which shows the effectiveness of the proposed technique up to rotational speeds as high as 1.2 million rpm.

\section{Background}

\subsection{Overview on high-speed achievements}

In order to situate the presented work, an overview of highspeed achievements is given, which have been attained by making use of various bearing technologies. For the purpose of comparison between systems of different sizes, we adopt the DN-number as a measure of the achieved rotational speed. The DN-number is defined as the product of the diameter in millimetres and the rotational speed in rpm, and is in fact a measure of the circumferential speed at the bearing surface.

In 1946, Beams and Young set the absolute record in terms of rotational speed with a $0.521 \mathrm{~mm}$ diameter hardened steel ball suspended magnetically in vacuum and spun by a rotating magnetic field. A rotational rate of $633 \mathrm{kHz}\left(=38 \times 10^{6} \mathrm{rpm}\right)$ was achieved, corresponding to a circumferential speed of approximately $1000 \mathrm{~m} \mathrm{~s}^{-1}$ ([14], table 1). The limitation in this case was not set by the bearing technology, but by the load limit of the rotor material. The rotor supposedly withstood stresses up to $2.9 \mathrm{GPa}$. As this value appears to be very high for the state of technology at that time, this achievement has often been questioned [5]. Table 1 lists the high-speed achievements as 
found in the open literature in order of increasing DN-number. In this way, the limitations of the different bearing technologies become apparent. Up to rotational speeds of ca $3 \times 10^{6} \mathrm{DN}$, ball bearing technology may offer a solution $[6,7]$. Values as high as $10 \times 10^{6} \mathrm{DN}$ can be obtained by making use of different types of gas bearings. At this point, viscous frictional losses prevail. Even greater speeds are attained by resorting to lowviscosity gases (hydrogen) or even magnetically suspended rotors in vacuum. The work presented in this paper amounts to an achievement of $7.2 \times 10^{6} \mathrm{DN}$ which represents to our knowledge a record for gas bearings of the self-acting type. The remainder of this paper will outline the modelling process, manufacturing aspects and experimental results leading to this achievement.

\subsection{Stability problem of high-speed gas bearings}

As is generally known, gas bearings are prone to a self-excited whirl instability when operated at high speed. Their successful application requires therefore a sound understanding of this phenomenon to identify the relevant parameters and to propose remedies that postpone or overcome the onset of self-excited whirling.

Self-excited whirling is the result of a dynamic instability that occurs in case of a lack of overall damping in the rotordynamic system. It is generally accepted that the crosscoupled stiffness in the supporting gas film gradually decreases the overall damping of the system as the rotational speed increases [15]. At a certain speed, the system is in a neutral state of stability (i.e. undamped eigenmode). This point is referred to as the onset or threshold speed. A further increase in rotational speed will induce sudden and violent whirling at a subsynchronous frequency that is equal to an eigenfrequency of the rotor-bearing system. In most plain bearing geometries, the onset speed of self-excited whirling lies close to twice the first (and lowest) eigenfrequency of the system, which explains the term half-speed or halffrequency whirling (although it is more correct to use the term subsynchronous self-excited whirling). The self-excited nature of this instability disciminates it from synchronous whirl, which is in effect the passive response to residual rotor imbalance.

The following analysis will confirm the aforementioned statements and will allow us to formulate a simple, yet effective stability criterion. Let us, for that purpose, state the basic equations of motion for the case of a simple rotor-bearing system consisting of a single rotor disc supported by a bearing with a rigid mount. By adopting the notation of figure 2 in which the dynamic film reaction force is given by

$$
\left\{\begin{array}{l}
f_{x} \\
f_{y}
\end{array}\right\}=\left[\begin{array}{ll}
k_{x x} & k_{x y} \\
k_{y x} & k_{y y}
\end{array}\right] \cdot\left\{\begin{array}{l}
x \\
y
\end{array}\right\}+\left[\begin{array}{ll}
c_{x x} & c_{x y} \\
c_{y x} & c_{y y}
\end{array}\right] \cdot\left\{\begin{array}{l}
\dot{x} \\
\dot{y}
\end{array}\right\},
$$

with the dynamic film coefficients $k_{i j}$ and $c_{i j}$ depending on the film geometry, steady-state working condition of the film (rotor speed $\omega$, eccentricity, etc) and on the perturbation frequency $v$, the equations of motion take the form

$$
\begin{aligned}
& m \ddot{x}+c_{x x} \dot{x}+c_{x y} \dot{y}+k_{x x} x+k_{x y} y=0, \\
& m \ddot{y}+c_{y y} \dot{y}+c_{y x} \dot{x}+k_{y y} y+k_{y x} x=0 .
\end{aligned}
$$

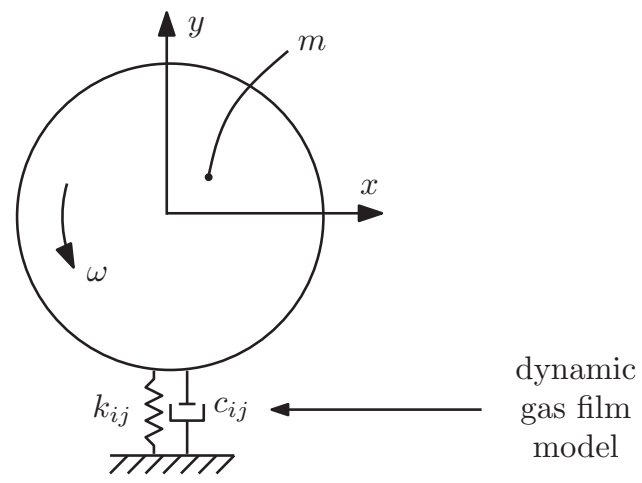

Figure 2. Dynamic model of a rotor-bearing system with a rigid bearing support.

In the general case, all eight coefficients are distinct. When the steady-state eccentricity approaches zero (a condition which is true for unloaded vertical rotors, or by approximation also applicable to other situations), symmetry exists in the gas film geometry, which reduces the full set of eight coefficients to four by the fact that

$$
\begin{aligned}
k_{i i}=k_{x x}=k_{y y} ; & k_{i j}=k_{x y}=-k_{y x}, \\
c_{i i}=c_{x x}=c_{y y} ; & c_{i j}=c_{x y}=-c_{y x} .
\end{aligned}
$$

This assumption of symmetry simplifies the previous set of equations to

$$
\begin{aligned}
& m \ddot{x}+c_{i i} \dot{x}+c_{i j} \dot{y}+k_{i i} x+k_{i j} y=0, \\
& m \ddot{y}+c_{i i} \dot{y}-c_{i j} \dot{x}+k_{i i} y-k_{i j} x=0 .
\end{aligned}
$$

The two coupled equations are converted into one single equation by the introduction of a whirl vector $z=x \pm \mathrm{i} y$. To this end, first divide through the rotor mass $m$ and by using the ratios $\kappa=k_{i j} / k_{i i}$ and $\gamma=c_{i j} / c_{i i}$ the above equations become

$$
\begin{aligned}
\ddot{x}+\frac{c_{i i}}{m} \dot{x}+\frac{c_{i j}}{m} \dot{y}+\omega_{n}^{2} x+\kappa \omega_{n}^{2} y & =0, \\
\ddot{y}+\frac{c_{i i}}{m} \dot{y}-\frac{c_{j i}}{m} \dot{x}+\omega_{n}^{2} y-\kappa \omega_{n}^{2} x & =0,
\end{aligned}
$$

with $\omega_{n}=\sqrt{k / m}$ being the natural frequency of the system. Then, by normalizing the time $t$ to $\tau=\omega_{n} t$ (a derivative with respect to $\tau$ is represented by $x^{\prime}$ )

$$
\begin{gathered}
x^{\prime \prime}+2 \zeta_{n} x^{\prime}+2 \gamma \zeta_{n} y^{\prime}+x+\kappa y=0, \\
y^{\prime \prime}+2 \zeta_{n} y^{\prime}-2 \gamma \zeta_{n} x^{\prime}+y-\kappa x=0,
\end{gathered}
$$

in which $\zeta_{n}$ is the damping ratio of the system defined as $\zeta_{n}=c_{i i} /\left(2 m \omega_{n}\right)$. Finally, the whirl vector $z=x+\mathrm{i} y$ is introduced. To this, a physical interpretation can be attributed by assuming forward circular whirling in the (complex) $x y$ space. When dealing with a sinusoidal whirling response, the first and second derivatives of $z$ appear as

$$
\begin{aligned}
z^{\prime} & =\mathrm{i} v z=v(\mathrm{i} x-y), \\
z^{\prime \prime} & =\mathrm{i} v z^{\prime}=v\left(\mathrm{i} x^{\prime}-y^{\prime}\right),
\end{aligned}
$$


where $v$ stands for the vibration frequency (normalized with respect to $\left.\omega_{n}\right)$. A summation of equation ( $6 a$ ) and the complex valued equation $(6 b)$ then yields one single equation of motion:

$$
\left(1-\frac{2 \gamma \zeta_{n}}{v}\right) z^{\prime \prime}+\left(2 \zeta_{n}-\frac{\kappa}{v}\right) z^{\prime}+z=0 .
$$

From this equation it seems that the cross-coupled damping appears as a mass contribution, and therefore only changes the natural frequency of the system to a small extent $\left(\gamma \zeta_{n} \ll 1\right)$. There is no direct effect on the stability characteristics of the system. By setting $\gamma$ to zero, we obtain a much more elegant equation:

$$
z^{\prime \prime}+(\underbrace{2 \zeta_{n}-\frac{\kappa}{v}}_{\zeta}) z^{\prime}+z=0 .
$$

The neutral stability condition of the system is given by

$$
2 \zeta_{n}-\frac{\kappa}{v}=0
$$

Since the system eigenfrequency will coincide with its undamped natural frequency $\omega_{n}$ in this neutrally stable state, the above condition translates to

$$
2 \zeta_{n}-\kappa=0
$$

or

$$
\kappa=2 \zeta_{n} .
$$

This one equation characterized by only two system parameters, $\zeta_{n}$ and $\kappa$, describes the (linear) dynamic behaviour of a symmetrical rigid rotor on air bearings. Although simple in form, it embodies the basic features which distinguish self-excited whirling: (i) the cross-coupled stiffness acts as negative damping to the system; (ii) this compromises the overall damping $\zeta$ and causes an instability to set in when $\zeta=0$ or $\kappa=2 \zeta_{n}$; (iii) this instability will appear as selfexcited whirling at the natural frequency $\omega_{n}$ of the system. A similar analysis can be performed for the backward whirl vector $z=x-\mathrm{i} y$.

A convenient stability criterion that will allow us to reason on the effect of the various parameters involved in the problem follows directly from the above analysis:

$$
\left|k_{i j}\right| \leqslant \sqrt{\frac{k_{i i}}{m}} c_{i i} .
$$

\subsection{Stabilization strategies: a brief overview}

The above analysis has clearly identified the cross-coupled stiffness as the driving force of the instability. This crosscoupling only increases with speed since it originates from aerodynamic film action. The film damping capacity, on the other hand, decreases due to the compressibility effect (at infinitely high perturbation frequencies a gaseous film offers no damping ${ }^{1}$ ). At a certain operating point, the film damping is unable to oppose the destabilizing forces generated in the film resulting in the onset of self-excited whirl. When observing

\footnotetext{
1 At very large values of the perturbation frequency, the pressure distribution approaches the so-called trapped gas case, i.e. where the gas film does not have time to flow anymore, but is rather purely compressed as described by Boyle's law.
}

this typical behaviour of the dynamic film coefficients as a function of speed, the occurrence of self-excited whirl seems inevitable when no measures are taken.

For that reason, various bearing geometries and configurations have been developed in order to overcome or at least postpone the onset of self-excited whirling. A detailed overview and discussion of these measures would be outside the scope of this paper. For this purpose, the reader is referred to $[16,17]$. We will limit ourselves for the moment by classifying the measures for enhancing the stability into two categories. A first category aims at enhancing the bearing stability by taking measures within the gas film itself, while the other category reverts to measures taken outside the supporting film.

- Measures taken within the gas film. These measures focus on an optimal design of the film geometry of the bearing in order to increase its direct stiffness and/or damping characteristics (hereby increasing the righthand side of equation (13)). This is in most cases accomplished by a proper selection of the nominal design parameters (clearance value, slenderness ratio, etc) or by the incorporation of surface features such as steps or pumping grooves.

With this method, satisfactory behaviour in terms of stability is only obtained by reverting to relatively small values of the clearance gap $h$. This increase in stability can be explained by observing the behaviour of the cross-coupled stiffness $k_{i j}$, direct stiffness $k_{i i}$ and direct damping $c_{i i}$ at decreasing clearance values. When dealing with low steady-state working eccentricities and the case of aerodynamic film action, all three coefficients generally scale with $1 / h^{3}$. According to the aforementioned stability criterion (equation (13)), this results in a more stable system since the right part increases more than the destabilizing cross-coupling in the left part.

Furthermore, the damping capacity is always limited at high frequencies due to the compressibility effect. For these reasons, this first category of measures might be regarded as a way to postpone the onset of self-excited whirl rather than overcoming it.

- Measures taken outside the gas film. In this case, the destabilizing cross-coupling effect generated within the gas film is compensated for outside the gas film. This category holds bearing configurations that incorporate a flexible, damped support of the bearing bush. The method of introducing external damping is a fundamental solution to the stability problem encountered in high-speed gas bearings, since it does not rely solely on the damping capacity of the gas film itself.

\section{Stabilization by means of a flexible, damped support}

The idea of stabilization by means of a flexible damped, support is certainly not new. Implementations for providing external damping to a rotor-bearing system exist in various forms. The most widespread implementation is found in oil-based squeeze-film dampers as a support for rolling 


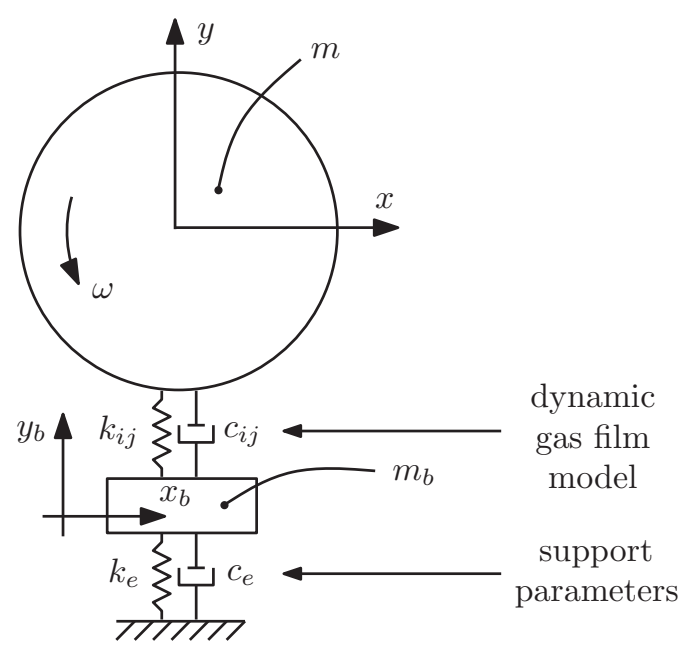

Figure 3. Dynamic model of a rotor-bearing system with a flexible, damped support.

element bearings in aircraft gas turbine engines to bound rotor vibrations through critical speeds [18]. In the field of gas bearings, a common implementation consists of an externally pressurized bearing bush supported by an elastomeric material such as rubber O-rings.

The remainder of this section will formulate design guidelines for a proper selection of the support parameters after which the proposed implementation is outlined.

\subsection{Optimal design of the bearing support}

As already stated by Lund [19], the improvement of the stability may only be affected by a proper choice of the support parameters. Nevertheless, no generally applicable design guidelines are found in the literature. The following study will therefore investigate how the support stiffness, damping and bush mass influence the bearing stability. To this end, the model used for a rigidly supported bearing is extended to take into account the effect of a flexible support (figure 3). The dynamic gas film model remains unchanged and is coupled in series to a support model through the mass of the floating bearing bush $m_{\mathrm{b}}$. For the following stability study, we assume a constant support stiffness coefficient $k_{e}$ and damping coefficient $c_{e}$, which act in a uniform way for all directions of motion. The absolute position of the floating ring is denoted by $\left(x_{b}, y_{b}\right)$.

By assuming symmetry in the gas film, by neglecting the effect of cross-coupled damping and by using the relations $\delta x=x-x_{b}, \delta y=y-y_{b}$, the set of equations of motion for this 4-dof system is easily composed as

$$
\begin{gathered}
m \ddot{x}+c_{i i} \dot{\delta} x+k_{i i} \delta x+k_{i j} \delta y=0, \\
m \ddot{y}+c_{i i} \dot{\delta} y+k_{i i} \delta y-k_{i j} \delta x=0, \\
m_{\mathrm{b}} \ddot{x}_{b}+c_{e} \dot{x}_{b}+k_{e} x_{b}-c_{i i} \dot{\delta} \dot{x}-k_{i i} \delta x-k_{i j} \delta y=0, \\
m_{\mathrm{b}} \ddot{y}_{b}+c_{e} \dot{y}_{b}+k_{e} y_{b}-c_{i i} \dot{\delta} y-k_{i i} \delta y+k_{i j} \delta x=0 .
\end{gathered}
$$

To minimize the number of variables and to arrive at conclusions which are widely applicable, a set of dimensionless parameters is searched for. The gas film and rotor properties are for this purpose best expressed as

$$
\zeta_{n}=\frac{c_{i i}}{2 m \omega_{n}} ; \quad \kappa=\frac{k_{i j}}{k_{i i}},
$$

with $\omega_{n}$ being the natural frequency of the rotor-bearing system, $\zeta_{n}$ the damping ratio of the system and $\kappa$ the ratio of cross-to-direct stiffness. The latter is a measure of the intrinsic quality of the bearing in terms of its tendency towards self-excited whirling. It is important to mention that these parameters reflect the dynamic properties of the rotor-bearing system only, without consideration of the external support structure. The support properties, on the other hand, are best related to the rotor and gas film properties in the following way:

$$
M_{b}=\frac{m_{\mathrm{b}}}{m} ; \quad K_{e}=\frac{k_{e}}{k_{i i}} ; \quad C_{e}=\frac{c_{e}}{c_{i i}} .
$$

This amounts in total to five dimensionless parameters which fully characterize the rotor-bearing-support system. By using these parameters and in a way similar as above, the set of equations of motion can now be rewritten as

$$
\begin{gathered}
x^{\prime \prime}+2 \zeta_{n} \delta x^{\prime}+\delta x+\kappa \delta y=0, \\
y^{\prime \prime}+2 \zeta_{n} \delta y^{\prime}+\delta y-\kappa \delta x=0 \\
M_{b} x_{b}^{\prime \prime}+2 C_{e} \zeta_{n} x_{b}^{\prime}+K_{e} x_{b}-2 \zeta_{n} \delta x^{\prime}-\delta x-\kappa \delta y=0 \\
M_{b} y_{b}^{\prime \prime}+2 C_{e} \zeta_{n} y_{b}^{\prime}+K_{e} y_{b}-2 \zeta_{n} \delta y^{\prime}-\delta y+\kappa \delta x=0 .
\end{gathered}
$$

Now, the stability of this system is evaluated for different combinations of the support parameters $\left(K_{e}, C_{e}\right)$, while subsequently varying the other parameters $M_{\mathrm{b}}, \kappa$ and $\zeta_{n}$. The set of equations stated above yields four solutions, each representing an eigenmode or whirling mode of the system. The stability is hereby determined by the damping ratio of the least stable eigenmode, i.e. the mode with the lowest damping ratio. For the sake of simplicity, the dynamic film parameters are assumed to be independent of the perturbation frequency

The corresponding results are summarized in figure 4 by means of iso-damping lines (lines of equal damping ratio). This way of presenting the data not only provides information on the stability region itself, which is contained with the lines of $\zeta=0$, but also reveals the degree of stability within this region. The top $(a)$, middle $(b)$ and bottom rows $(c)$ of the figure, respectively, clarify the effect of the bush mass $M_{\mathrm{b}}$, cross-coupling ratio $\kappa$ and damping ratio $\zeta_{n}$ on the optimal choice of $\left(K_{e}, C_{e}\right)$. The set of figures should, as a whole, allow for the optimal choice of the support parameters, i.e. $\left(K_{e}, C_{e}\right)=f\left(M_{b}, \kappa, \zeta_{n}\right)$.

The below set of design guidelines can be formulated from these results. Because of the dimensionless formulation, these guidelines are applicable to flexible, damped rotordynamic systems irrespective of physical dimension, bearing type, etc. However, they must be regarded as a rule of thumb rather than as a guarantee for stability. In its final stage, the design process should therefore be backed by a more extensive stability evaluation for various operation conditions and by taking into account the frequency-dependent gas film behaviour (see for example [20]). 
(a) Effect of bush mass $M_{b}$ :

(for $\kappa=1, \zeta_{n}=0.05$ )

(b) Effect of cross-coupling $\kappa$ :

(for $M_{b}=0.1, \zeta_{n}=0.05$ )

(c) Effect of gas film damping $\zeta_{n}$ : (for $M_{b}=0.1, \kappa=1$ )
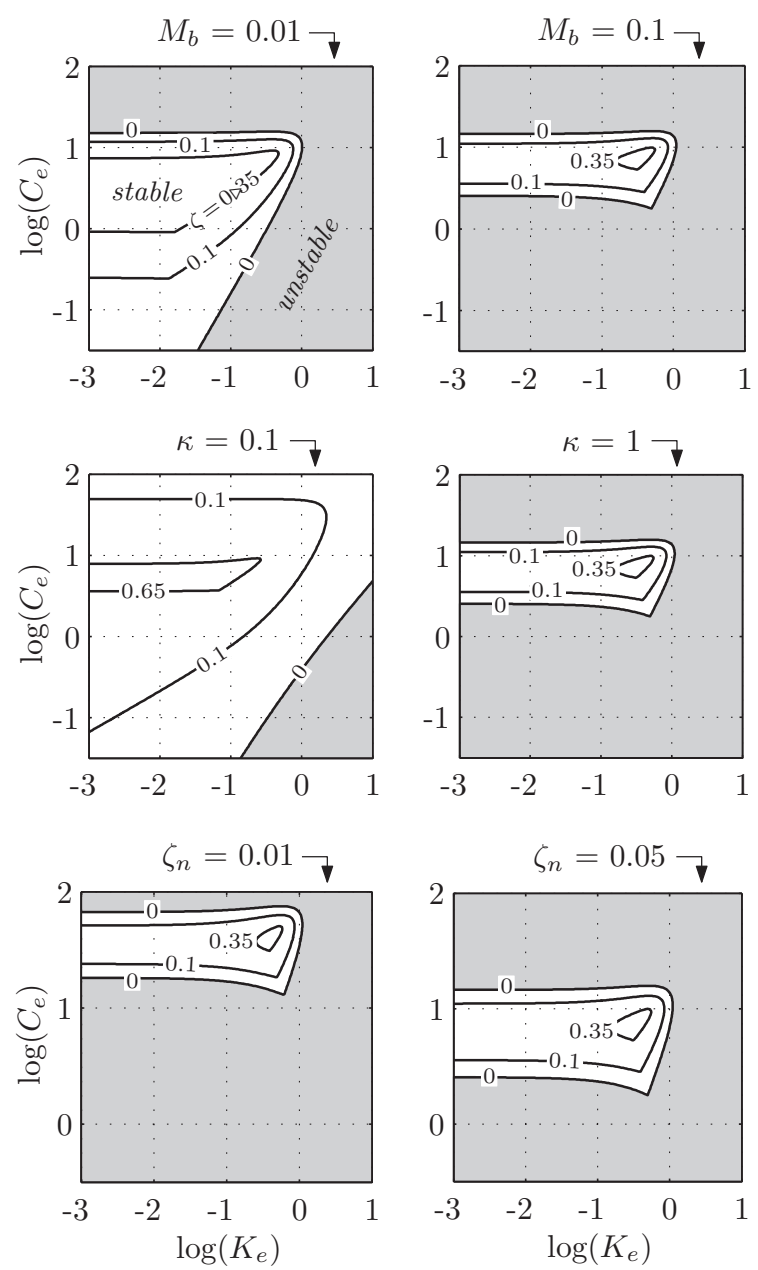
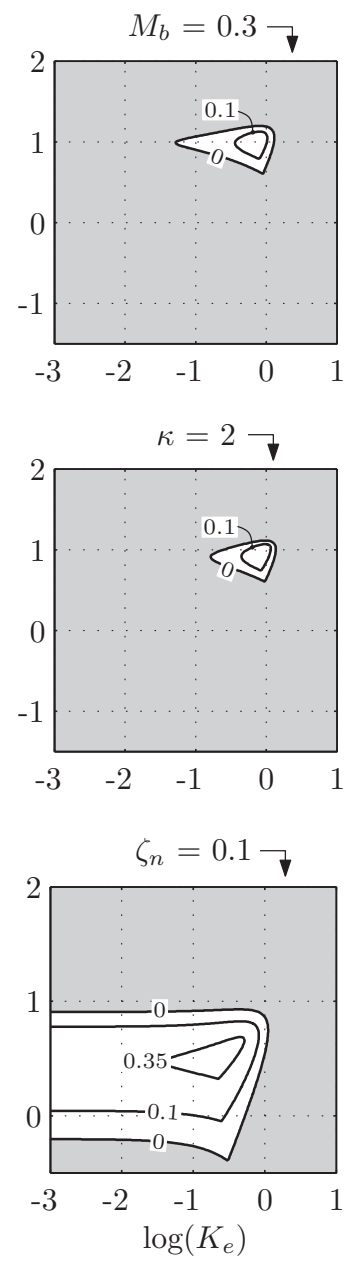

Figure 4. Damping ratio of the least stable whirling for different values of the dimensionless support stiffness $K_{e}$ and damping $C_{e}$. The top row $(a)$, middle row $(b)$ and bottom row $(c)$ of the figure respectively show the effect of the bush mass $M_{\mathrm{b}}$, cross-coupling ratio $\kappa$ and damping ratio $\zeta_{n}$ on the optimal choice of $\left(K_{e}, C_{e}\right)$.

- As for the optimal choice of support parameters $m_{\mathrm{b}}, k_{e}$ and $c_{e}$ given the dynamic gas film properties and rotor mass $m$, the following qualitative guidelines hold true: (i) in order to obtain a wide region of stable behaviour in terms of support stiffness and damping, try to keep the bush mass $m_{\mathrm{b}}$ ten times smaller than the rotor mass $m$, i.e. $M_{b} \leqslant 0.1$; (ii) design the support structure in such a way that it provides an external stiffness $k_{e}$ which is certainly smaller than the gas film stiffness itself, preferably by a factor of 2-3, thus $K_{e} \leqslant 0.5$ or better $K_{e} \leqslant 0.3$; and (iii) depending on the amount of gas film damping, decide on the proper amount of external damping $c_{e}$ to be added, which lies mostly in the range $2<C_{e}<20$.

- A proper design of the gas film geometry should prevent the cross-coupled stiffness $k_{i j}$ from exceeding the direct stiffness $k_{i i}$, leading to the requirement $\kappa \leqslant 1$. By following this guideline and by satisfying $M_{b} \leqslant 0.1$, the conditions for a proper selection of the support parameters are significantly relaxed.

\subsection{Proposed implementation}

The literature reveals various ways of introducing external damping to a rotor-bearing system. First, there are the implementations that make use of an elastomeric material to support the bearing bush. Early work has been performed by Powell et al [21] on the O-ring support of an aerostatic bearing for a dental drill running at speeds up to $720000 \mathrm{rpm}$. Kazimierski et al [22] characterized the dynamic behaviour of different rubber materials and investigated the effect on the stability. Also, interesting within the context of this paper is the work performed by Tomioka et al [23]. They were able to attain, with a miniature spiral-groove journal bearing on rubber O-rings, a rotational speed of $509000 \mathrm{rpm}\left(=3.054 \times 10^{6} \mathrm{DN}\right)$. When using an elastomeric support, the difficulty remains in the characterization of the complex visco-elastic behaviour of the support material and its dependence on temperature. Another source of damping may be found in the dry (Coulomb) friction existing in elements of the support structure, as used in, for example, $[24,25]$. In the case of foil bearings, this is one of the key factors that contribute to their superior stability properties. However, the manufacturing process of this kind of support structure does not always yield controllable and 


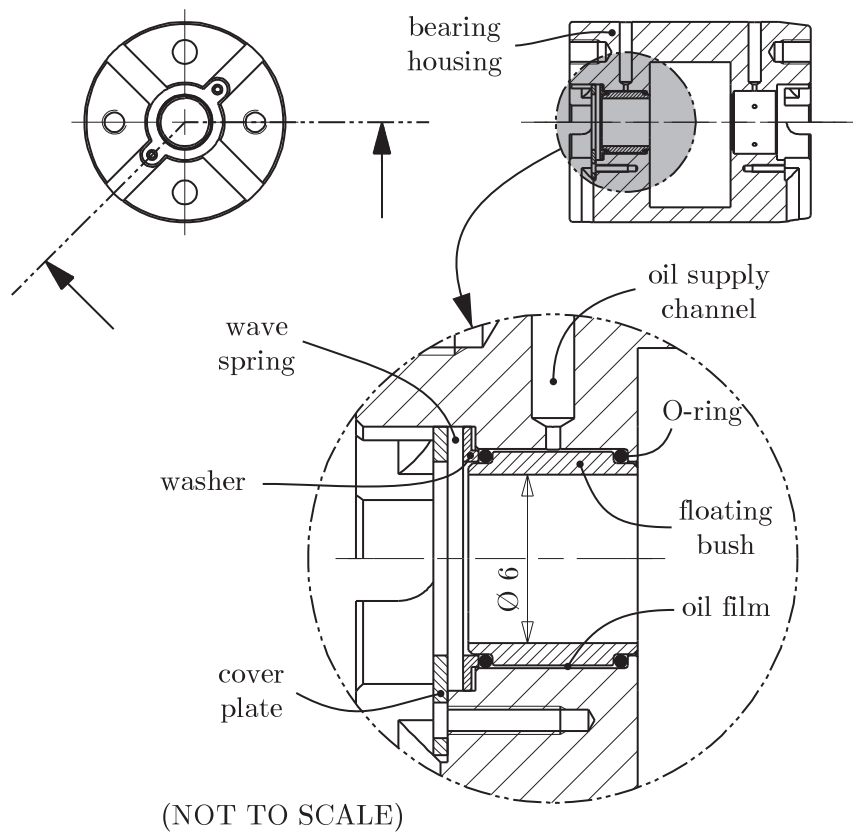

Figure 5. Revolved sectional view of the bearing unit revealing the implementation of the flexible, damped support. See also the detailed view of figure 7 .

reliable properties, and certainly not at a miniature scale. Finally, a last method of introducing damping is by means of a squeeze-film damper such as found in the support of bearings of aircraft jet engines. The application of this kind of damper to air bearing systems is however not very common.

In the implementation proposed here, the external damping originates from visco-elastic properties of the support in combination with a tunable squeeze-film damper. As shown in figure 5 , the bearing bush is supported by rubber O-rings which provide in the support stiffness and partly account for the external damping (type Apple Rubber $6.80 \mathrm{~mm} \times 0.50 \mathrm{~mm}$ : nitrile 70 shore and silicone 25 shore). They however also serve as a seal for an oil-filled squeeze-film cavity. The amount of damping that is introduced in this way to the system can be controlled accurately by varying the oil viscosity (from 1 to $150 \mathrm{cSt}$ ). The support stiffness may be adjusted to a certain extent by changing the O-ring preload applied by a wave spring. The tunability of the support parameters will allow us to conduct experiments to verify the aforementioned design guidelines.

As stated above, the bearing characteristics must meet certain requirements in order for the damped support to be effective. First of all, the gas film should possess a direct stiffness value higher than the support stiffness $\left(K_{e} \leqslant 0.5\right)$. Second, the cross-coupled stiffness should not exceed the direct stiffness $(\kappa \leqslant 1)$. Although an externally pressurized bearing type would meet these requirements best, complications encountered in the practical realization of the air supply through the squeeze film make us revert to aerodynamic (self-acting) geometries.

Figure 6 shows the film geometry and corresponding notation of the bearing designed to meet the above requirements. Pressure is generated by means of a series

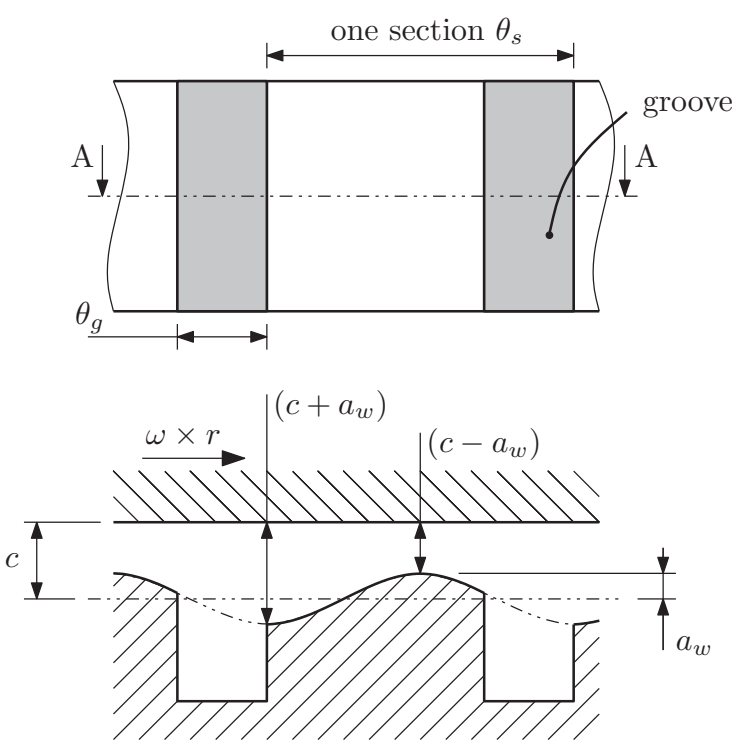

(Sectional view $\mathrm{A}-\mathrm{A})$

Figure 6. Film geometry and corresponding notation of the aerodynamic bearing (developed view). The design parameters can be found in table 2 .

Table 2. Design parameters of the aerodynamic bearing and estimated error based on the dimensional control of a series of bearing bushes (see figure 6 for notation).

\begin{tabular}{lrl}
\hline & Design & As built \\
\hline Bearing radius $r(\mathrm{~mm})$ & 3 & - \\
Bearing length $L(\mathrm{~mm})$ & 6 & $6 \pm 0.1$ \\
Radial clearance $c(\mu \mathrm{m})$ & 10 & $10 \pm 2$ \\
Wave amplitude $a_{w}(\mu \mathrm{m})$ & 5 & $5 \pm 1$ \\
Section angle $\theta_{s}(\mathrm{deg})$ & 120 & - \\
Groove angle $\theta_{g}(\mathrm{deg})$ & 36 & $36 \pm 2$ \\
\hline
\end{tabular}

of converging film sections, in this case with a sinusoidal shape. The geometry has some resemblance to lobed or wave-shaped geometries as reported in [26, 27], although the geometry proposed here features a significantly lower cross-coupled stiffness value due to the removal of the diverging film sections (in addition, this also reduces the frictional losses by ca 20\%). For the design parameters

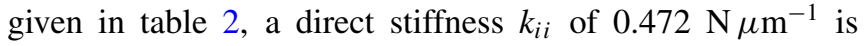
predicted, while the cross-coupled stiffness $k_{i j}$ only reaches

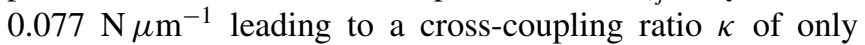
0.163 (at a rotational speed of $500000 \mathrm{rpm}$, half-synchronous perturbation frequency and obtained with a finite-difference solution of the compressible Reynolds equation). A second interesting feature of the geometry proposed here concerns the ability to be manufactured accurately at a miniature scale with conventional techniques, as will be illustrated further on.

\section{Experimental results}

This section will first describe the test setup used for the experiments. Hereafter, the influence of the support stiffness and damping on the stability is analysed. After the 


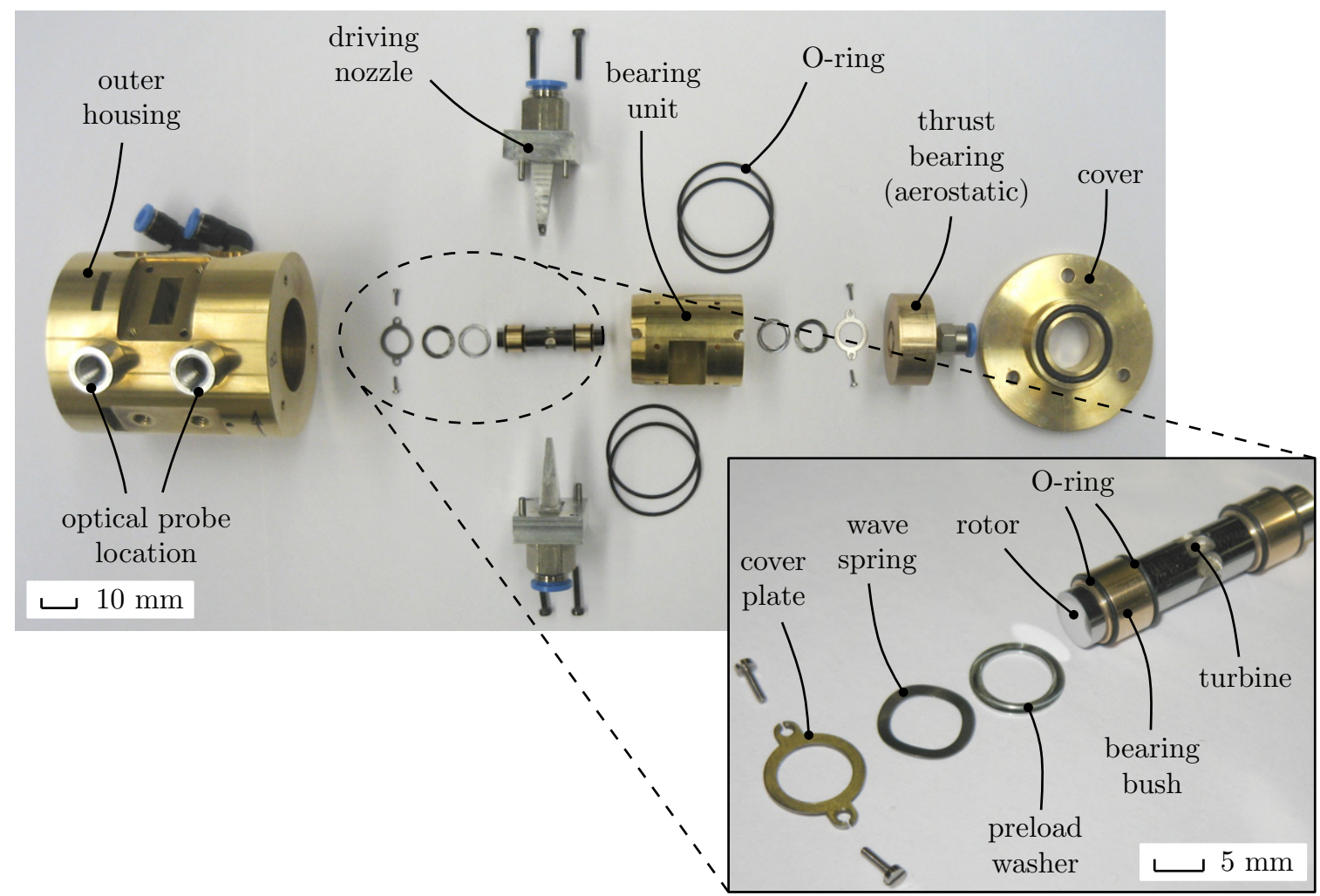

Figure 7. Components of the test setup before assembly and detailed view of the rotor-bearing configuration.

determination of the optimal combination of support stiffness and damping, a run-up experiment has been performed up to a speed of 1.2 million rpm. To conclude, the total frictional loss is obtained from a deceleration experiment and the relative contribution of the different contributions is quantified.

\subsection{Test apparatus}

The different components of the test setup are shown in figure 7. The core unit consists of a hardened steel rotor (diameter $6 \pm 0.0003 \mathrm{~mm}$, length $30 \mathrm{~mm}$ and mass $m=6.67 \mathrm{~g}$ ), which is supported by two aerodynamic journal bearings with parameters as described in table 2 and by two centrally fed aerostatic thrust bearings. The rotor is driven by a Pelton turbine to the required speed. The complete core unit fits into a housing part. Instrumentation consists of a speed/trigger sensor (MTI KD310) and two in-house developed fibre-optic displacement transducers located at both ends of the rotor. The acquired signals are analysed in real time in the frequency domain in order to detect self-excited whirling.

\subsection{Bearing manufacturing process}

The wave-shaped film height geometry is realized by a controlled elastic deformation, while clamping the bearing bush during the finishing machining step on a precision lathe (SPINNER SB-C). For this purpose, the bearing bush is held in a dedicated clamping part, which in turn is placed in a W25 machining collet (figure $8(a)$ ). The elastic deformation is controlled by adjusting the force exerted by the pneumatic clamping unit. The points where the bush is in contact with

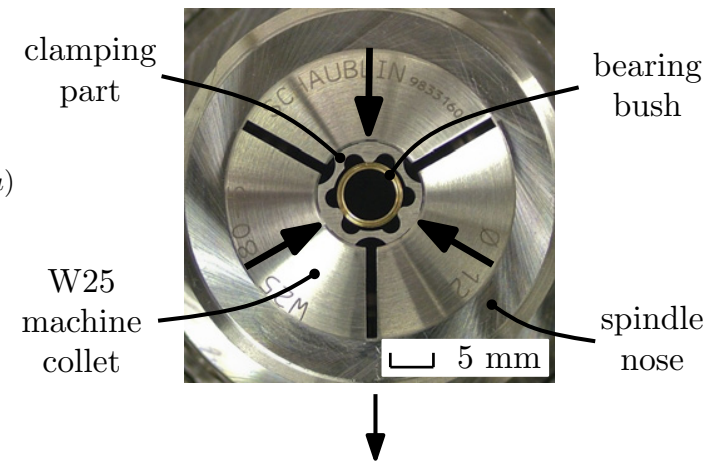

Diverging sections removed by wire-EDM

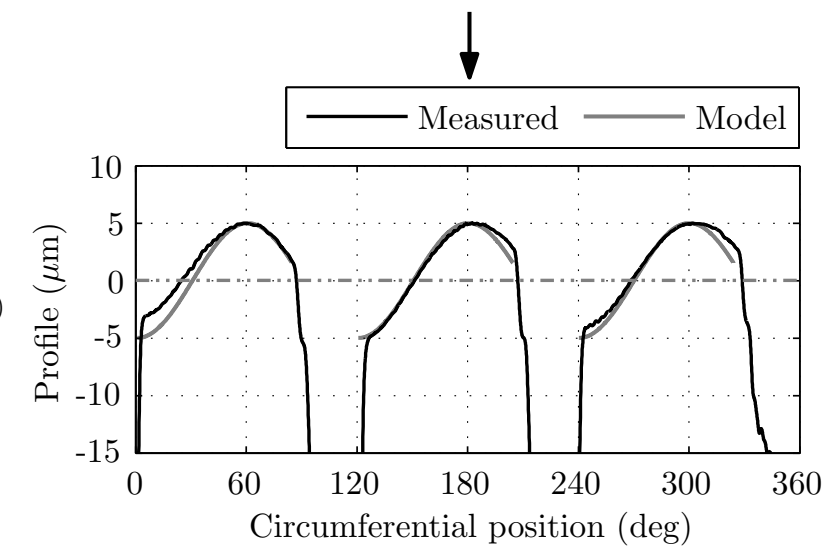

Figure 8. Fabrication process of the bearing bushes: $(a)$ controlled elastic deformation to create a wave-shaped profile; $(b)$ comparison of the measured height profile against the model profile. 
Table 3. Threshold speed and corresponding whirl frequency for different combinations of support stiffness and damping (for bearing geometry of table 2, bush mass $m_{\mathrm{b}}$ of $0.74 \mathrm{~g}$ and nitrile rubber O-rings 70 shore).

\begin{tabular}{llll}
\hline $\begin{array}{l}\text { Support } \\
\text { stiffness }^{\mathrm{a}} \\
\left(\mathrm{N} \mu \mathrm{m}^{-1}\right)\end{array}$ & $\begin{array}{l}\text { Oil } \\
\text { viscosity } \\
(\mathrm{cSt})\end{array}$ & $\begin{array}{l}\text { Thresh. } \\
\text { speed }^{\mathrm{b}} \\
(\mathrm{rpm})\end{array}$ & $\begin{array}{l}\text { Whirl } \\
\text { frequency } \\
(\mathrm{Hz})\end{array}$ \\
\hline \multirow{4}{*}{0.04} & $\begin{array}{l}\text { no oil } \\
10\end{array}$ & - & - \\
& 22 & - & - \\
& no oil & 120540 & 815 \\
& 1 & 136320 & 870 \\
0.14 & 5.3 & 145200 & 887 \\
& 22 & - & - \\
& 32 & 169560 & 1000 \\
\hline & no oil & 138000 & 922 \\
0.38 & 5.3 & 144300 & 942 \\
& 22 & 150000 & 970 \\
& 32 & 151200 & 990 \\
& 150 & 133800 & 927 \\
\hline
\end{tabular}

${ }^{a}$ Estimation based on the static deflection test.

${ }^{\mathrm{b}}$ Speed at which subsynchronous whirl amplitude reaches $1 \mu \mathrm{m}$.

- means that no subsynchronous whirl was observed

within the test speed range $(0-600000 \mathrm{rpm})$.

the clamping part will elastically deform, forming the troughs of the wave-shaped profile in the unclamped state. Hereafter, the gap height is increased to $100 \mu \mathrm{m}$ over a circumferential angle of $36^{\circ}$ by wire-EDM in order to induce atmospheric pressure at the diverging film sections. Figure $8(b)$ compares the film height profile obtained by this process against the profile used for the gas film model. The agreement is relatively good with an overall difference of $\pm 1 \mu \mathrm{m}$ up to $\pm 2 \mu \mathrm{m}$ locally. The asymmetry observed between the three profile sections is attributed to residual stresses in the material (bronze

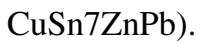

\subsection{Support parameters tuning}

In order to determine the optimal combination of support stiffness and damping, the threshold speed of self-excited whirling is observed, while varying the O-ring preload and oil viscosity. The support stiffness corresponding to the different amounts of preload is determined from a simple gravitational loading experiment. Therefore, they are rather rough quasi-static estimations of the complex dynamic stiffness behaviour. Nevertheless, this approach will enable us to identify qualitative trends from the experimental results. The amount of external damping is controlled by filling the squeeze-film cavity with oils of varying viscosity (ranging from $1 \mathrm{up}$ to $150 \mathrm{cSt}$ ). The amount of support damping realized by this oil film is calculated by means of a finite-difference solution of the Reynolds equation for incompressible fluids. For an oil viscosity of $1 \mathrm{cSt}$, this yields an equivalent damping of $0.78 \mathrm{~N} \mathrm{~s} \mathrm{~m}^{-1}$ (for a damper of radius $3.8 \mathrm{~mm}$, length $4.3 \mathrm{~mm}$ and radial clearance equal to $100 \mu \mathrm{m}$ ).

Table 3 shows the threshold rotor speed and corresponding whirl frequency for three values of the support stiffness $k_{e}$ and for various oil viscosities. For each combination, the rotor is gradually accelerated until self-excited whirl is observed. During the experiments, the threshold speed is defined as the rotor speed at which the whirl amplitude exceeds $1 \mu \mathrm{m}$. The following qualitative conclusion may be drawn from the results: (i) with exception of the lowest support stiffness, there exists for each support stiffness a value of the support damping that yields optimal stability; and (ii) the support stiffness may not exceed the gas film stiffness $\left(k_{i i}=0.17 \mathrm{~N} \mathrm{~m}^{-1}\right.$ at $150000 \mathrm{rpm}$ ) for external damping to be effective. These conclusions are in line with the outcome of the analysis of the previous section. A more qualitative comparison of the model with these experimental results is not performed due to the unknown (or rather difficult to estimate) amount of damping originating from the rubber support material. Furthermore, it appears that in the situation of the lowest support stiffness and no damping oil, sufficient damping is introduced by the visco-elastic behaviour of the rubber O-rings in order to obtain stable behaviour. Still, further experiments were performed with damping oil of $22 \mathrm{cSt}$, since this combination yields best results for the case of $k_{e} \simeq 0.14 \mathrm{~N} \mu \mathrm{m}^{-1}$.

\subsection{Experiment with a helium-driven turbine up to 1.2 million rpm}

After the determination of the optimal support parameters ( $k_{e} \simeq 0.04 \mathrm{~N} \mu \mathrm{m}^{-1}$, mineral damping oil $22 \mathrm{cSt}$ ), successful operation was demonstrated up to a rotational speed of $683280 \mathrm{rpm}\left(=4.1 \times 10^{6} \mathrm{DN}\right)$. Not the manifestation of selfexcited instabilities, but the limited driving power of the impulse turbine prevented reaching even higher speeds. In more recent experiments on the same bearing configuration (support stiffness $k_{e} \simeq 0.04 \mathrm{~N}_{\mu} \mathrm{m}^{-1}$, silicon damping oil $20 \mathrm{cSt}$ ), helium has been used to drive the turbine ${ }^{2}$. Due to the higher sonic outlet velocity (ca $1000 \mathrm{~m} \mathrm{~s}^{-1}$ ), the maximal attainable rotational speed could be increased to $1203000 \mathrm{rpm}$ $\left(=7.2 \times 10^{6} \mathrm{DN}\right)$. This achievement represents, to our knowledge, a record in terms of the DN-number for an air bearing of the self-acting type (table 1). The waterfall diagram recorded during this experiment is shown in figure 9. The traces of nonsynchronous whirl are the result of a measurement artefact as discussed in [12]. The measurement does not show any sign of self-excited whirling over the entire speed range, which points to the linear, stable behaviour of the system.

\subsection{Analysis of bearing and windage losses}

A deceleration experiment has been carried out to obtain an estimation of the frictional losses. To this end, the rotor is accelerated to nearly $700000 \mathrm{rpm}$ after which the supply to the driving turbine is closed instantly. The total frictional power loss and torque follow from an analysis of the measured speed versus time data (figure 10). The measured data are for this purpose first fitted with a sixth-order polynomial. The value of the polar moment of inertia used for the deceleration analysis is $30.00 \mathrm{~g} \mathrm{~mm}^{2}$.

2 Although the bearings operate in air, the high flow of helium from the turbine could change the composition of the gas in the supporting film. The dynamic viscosity of helium and air is however comparable, which would lead to similar bearing behaviour in terms of frictional losses and stability. 


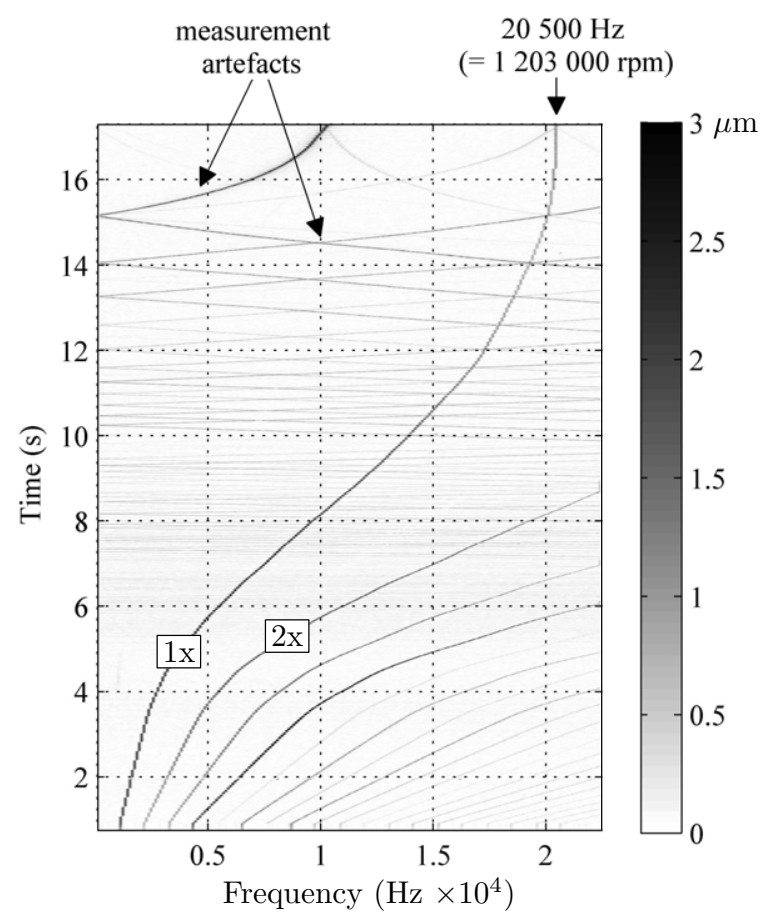

Figure 9. Waterfall diagram of a runup experiment up to $1203000 \mathrm{rpm}$. The synchronous whirl response is indicated by ' $1 \mathrm{x}$ '. The traces of nonsynchronous whirl are the result of a measurement artefact [12].

The total power loss of the system is the sum of the following individual components: (i) journal bearing losses, (ii) windage losses, (iii) thrust bearing losses and (iv) losses arising from the drive system. The relative importance of these loss sources is discussed below and is shown in figure 11 .

- Journal bearing losses. The frictional losses in the bearings can be split into a viscous and a hydrodynamic loss contribution. Both sources are included in the gas film model which assumes laminar viscous flow in the bearing gap. The calculated loss versus speed of a single

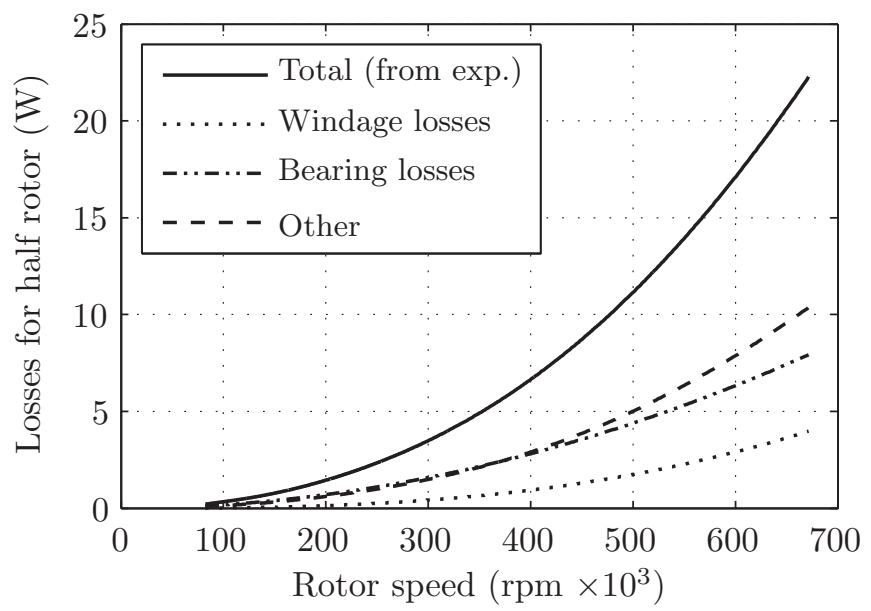

Figure 11. Relative contribution of the different frictional loss sources: total loss obtained from experiment (-); journal bearing losses $(-\cdots-)$; windage losses $(\cdots \cdots)$ ) and other (- - -).

journal bearing is plotted in figure 11. The centrifugal rotor growth is taken into account $(0.85 \mu \mathrm{m}$ radial growth at $700000 \mathrm{rpm}$ ).

- Windage losses. Due to the large air gap, the flow is no longer laminar when considering the losses induced at the non-bearing areas of the rotor. To estimate these so-called windage losses, the following relationship, based on the turbulent flow between to parallel plates, is used [28]:

$$
P_{\text {turb }}=\pi C_{d} \rho r^{4} \omega^{3} L,
$$

with $\rho$ being the density of the gas, $r$ the radius of the rotor, $L$ the axial length and $\omega$ the rotational speed. $C_{d}$ is the so-called skin friction coefficient which is obtained from the following empirical equation:

$$
\frac{1}{\sqrt{C_{d}}}=2.04+1.768 \ln \left(\operatorname{Re} \sqrt{C_{d}}\right)
$$

with the Reynolds number $R e$ defined as

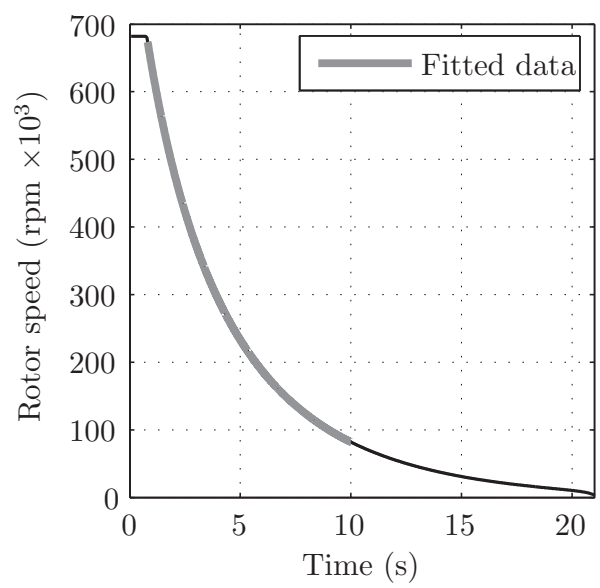

(a)

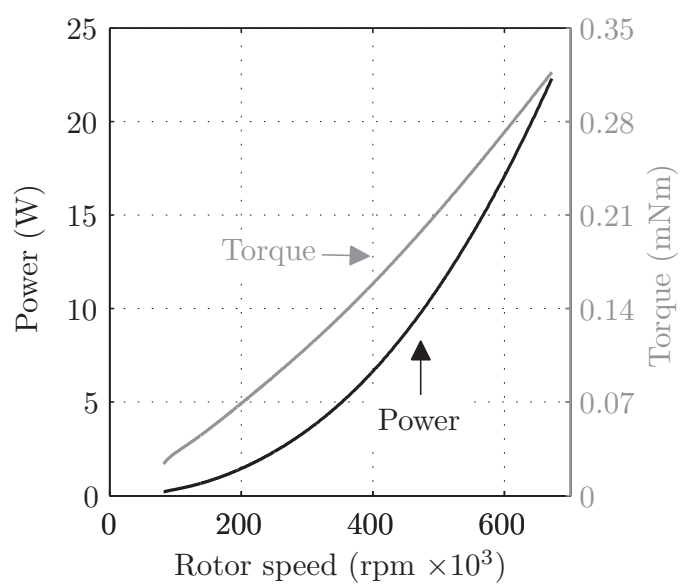

(b)

Figure 10. Outcome of a deceleration experiment to estimate the frictional losses (for half-rotor): $(a)$ measured speed versus time data and fitted curve; (b) total frictional power loss and torque. 


$$
\operatorname{Re}=\frac{\rho c r \omega}{\mu},
$$

in which $c$ equals the radial gap and $\mu$ the dynamic viscosity of the gas.

Equation (18) has been evaluated for increasing values of the rotational speed $\omega$. The length $L$ is hereby set at $9 \mathrm{~mm}$ (for half-rotor), while the average radial clearance value $c$ over this length is ca $3 \mathrm{~mm}$.

- Other loss sources: thrust bearings and turbine. The frictional losses attributed to the thrust bearings are rather limited $(0.4 \mathrm{~W}$ per bearing for a $30 \mu \mathrm{m}$ gap at $700000 \mathrm{rpm})$. The losses originating from the Pelton drive turbine, on the other hand, will be more significant, although a reasonable estimation of this loss source proves to be difficult. In figure 11, the curve indicating these losses is obtained by subtracting both the journal bearing and windage losses from the total measured frictional loss.

\section{Conclusions and future work}

In this paper, we have demonstrated the effectiveness of stabilization by means of a flexible, damped bearing support. Aspects concerning the design, implementation and manufacturing have been discussed in detail. Experimental results are reported up to rotational speeds as high as 1.2 million rpm, leading to a speed record of 7.2 million DN. Furthermore, deceleration experiments are conducted in order to estimate the frictional losses and to determine the relative contribution of the different loss factors.

\section{Acknowledgments}

The authors wish to acknowledge the IWT (Institute for the Promotion of Innovation by Science and Technology in Flanders).

\section{References}

[1] Gross W A, Matsch L A, Castelli V, Eshel A, Vohr J and Wildmann M 1980 Fluid Film Lubrication (New York: Wiley)

[2] Peirs et al 2007 Micropower generation with microgasturbines: a challenge J. Mech. Eng. Sci. 221 489-500

[3] Epstein A H 2009 Millimeter-scale, micro-electro-mechanical systems gas turbine engines J. Eng. Gas Turbines Power $126205-26$

[4] Schiffmann J and Favrat D 2009 Experimental investigation of a direct driven radial compressor for domestic heat pumps Int. J. Refrig. 32 1918-28

[5] Wildmann C, Nussbaumer T and Kolar J W 2010 Design considerations for the drive of an ultra-high speed spinning ball motor Proc. 20th Int. Symp. on Power Electronics, Electrical Drives, Automation and Motion (SPEEDAM) (Pisa, Italy) pp 1478-83

[6] Signer H, Bamberger E N and Zaretsky E V 1974 Parametric study of the lubrication of thrust loaded $120-\mathrm{mm}$ bore ball bearings to 3 million DN J. Lubr. Technol. $96515-26$
[7] Zwyssig C, Kolar J W and Round S D 2009 Megaspeed drive systems: pushing beyond 1 million r/min IEEE/ASME Trans. Mechatronics 14 564-74

[8] Schmid C 1974 Gas bearing turboexpanders for cryogenic plants Proc. 6th Int. Gas Bearing Symp. (Southampton, UK) paper B1 pp B1-1-B1-8

[9] Hikichi K, Goto S, Togo S, Tanaka S and Isomura K 2005 Hydroinertia gas bearings for micro spinners J. Micromech. Microeng. 15 228-32

[10] Hikichi K, Togo S, Isomura K, Saji N, Esashi M and Tanaka S 2009 Ultra-high-speed tape-type radial foil bearing for micro turbomachinery Proc. 9th Int. Workshop on Micro and Nanotechnology for Power Generation and Energy Conversion Applications (PowerMEMS 2009) (Washington, $D C$, USA) pp 79-82

[11] Teo C J, Liu L X, Li H Q, Ho L C, Jacobson S A, Ehrich F F, Epstein A H and Spakovszky Z S 2009 High-speed operation of a gas-bearing supported MEMS-air turbine J. Tribol. 131032001

[12] Waumans T, Peirs J, Al Bender F and Reynaerts D 2010 Aerodynamic journal bearing with a flexible, damped support operating at 7.2 million DN Proc. 10th Int. Workshop on Micro and Nanotechnology for Power Generation and Energy Conversion Applications (PowerMEMS 2010) (Leuven, Belgium) pp 199-202

[13] Beams J W 1938 High speed centrifuging Rev. Mod. Phys. $10245-63$

[14] Beams J W and Young J L 1946 Centrifugal fields Phys. Rev. 71131

[15] Frêne J, Nicolas D, Degueurce B, Berthe D and Godet M 1997 Hydrodynamic Lubrication-Bearings and Thrust Bearings (Amsterdam: Elsevier)

[16] Fuller D D 1969 A review of the state-of-the-art for the design of self-acting gas-lubricated bearings J. Lubr. Technol. 91 1-16

[17] Pan C H T 1980 Rotor-bearing Dynamics Technology Design Guide: part VI. Status of Gas Bearing Technology Applicable to Aero Propulsion Machinery Report ADA094167 (Ballston Lake, NY: Shaker Research Corp.) p 173

[18] Della Pietra L and Adiletta G 2002 The squeeze film damper over four decades of investigations: part 1. Characteristics and operating features Shock Vib. Dig. 34 3-26

[19] Lund J W 1965 The stability of an elastic rotor in journal bearings with flexible, damped supports $J$. Lubr. Technol. 87 911-20

[20] Waumans T, Vleugels P, Peirs J, Al Bender F and Reynaerts D 2006 Rotordynamic behaviour of a micro-turbine rotor on air bearings: modelling techniques and experimental verification Proc. Int. Conf. Noise and Vibration Eng. (ISMA 2006) (Leuven, Belgium) pp 181-98

[21] Powell J W and Tempest M C 1968 A study of high speed machines with rubber stabilized air bearings $J$. Lubr. Technol. 90 701-8

[22] Kazimierski Z and Jarzecki K 1979 Stability threshold of flexibly supported hybrid gas journal bearings J. Lubr. Technol. 101 451-7

[23] Tomioka J, Miyanaga N, Outa E, Takahashi T, Ogimoto T, Mori T and Kagami F 2007 Development of herringbone grooved aerodynamic journal bearings for the support of ultra-high-speed rotors Trans. JSME, Mach. Elem. Manuf. 73 1840-6

[24] Rimpel A and Kim D 2009 Rotordynamic performance of flexure pivot tilting pad gas bearings with vibration damper J. Tribol. 131021101

[25] Ertas B H 2009 Compliant hybrid journal bearings using integral wire mesh dampers J. Eng. Gas Turbines Power 131022503 
[26] Dimofte F 1995 Wave journal bearing with compressible lubricant: part 1 . The wave bearing concept and a comparison to the plain circular bearing Tribol. Trans. 38 153-60
[27] Pinkus O 1959 Analysis and characteristics of the three-lobe bearing J. Basic Eng. 81 49-55

[28] Vrancik J E 1968 Prediction of windage power loss in alternators NASA Technical Note TN D-4849 